\title{
On multi-valued weak quasi-contractions in b-metric spaces
}

\author{
Nawab Hussain ${ }^{a}$, Zoran D. Mitrovićb,* \\ ${ }^{a}$ Department of Mathematics, King Abdulaziz University, P. O. Box 80203, Jeddah 21589, Saudi Arabia. \\ ${ }^{b}$ University of Banja Luka, Faculty of Electrical Engineering, Patre 5, 78000 Banja Luka, Bosnia and Herzegovina.
}

Communicated by Z. Kadelburg

\begin{abstract}
We introduce some generalizations of the contractions for multi-valued mappings and establish some fixed point theorems for multi-valued mappings in b-metric spaces. Our results generalize and extend several known results in b-metric and metric spaces. Some examples are included which illustrate the cases when the new results can be applied while the old ones cannot. (C)2017 All rights reserved.
\end{abstract}

Keywords: Fixed points, b-metric space, set-valued mapping. 2010 MSC: 47H10.

\section{Introduction and preliminaries}

In the papers of Bakhtin [4] and Czerwik [10, 11], the notion of b-metric space has been introduced and some fixed point theorems for single-valued and multi-valued mappings in b-metric spaces proved. Successively, this notion has been reintroduced by Khamsi [18] and Khamsi and Hussain [19], with the name of metric-type space. Several results have appeared in metric-type spaces, we refer to [3, 9-16, 19, 23-26].

Definition 1.1. Let $X$ be a nonempty set and let $s \geqslant 1$ be a given real number. A function $d: X \times X \rightarrow[0, \infty)$ is said to be a b-metric with coefficient $s$ if and only if for all $x, y, z \in X$ the following conditions are satisfied:

(1) $d(x, y)=0$ if and only if $x=y$;

(2) $d(x, y)=d(y, x)$;

(3) $d(x, z) \leqslant s[d(x, y)+d(y, z)]$.

A triplet $(X, d, s)$ is called a b-metric space.

\footnotetext{
*Corresponding author

Email addresses: nhusain@kau.edu.sa (Nawab Hussain), zoran.mitrovic@etf .unibl.org (Zoran D. Mitrović)
} doi:10.22436/jnsa.010.07.35 
Note that a metric space is included in the class of b-metric spaces. The concept of convergence in such spaces is similar to that of the standard metric spaces. The b-metric space $(X, d, s)$ is called complete if every Cauchy sequence of elements from $(X, d, s)$ is convergent. Some examples of $b$-metric spaces can be seen in $[3,10,11]$.

Let $(X, d, s)$ be a b-metric space, let us denote $\mathrm{CB}(X)$ the collection of nonempty closed bounded subsets of $X$ and by $C L(X)$ the class of all nonempty closed subsets of $X$. For $x \in X$ and $A, B \in C L(X)$, we define

$$
d(x, A)=\inf _{a \in A} d(x, a), \quad D(A, B)=\sup \{d(a, B): a \in A\}
$$

Then the generalized Pompeiu-Hausdorff b-metric $\mathrm{H}$ on $\mathrm{CL}(\mathrm{X})$ induced by $d$ is defined as

$$
H(A, B)= \begin{cases}\max \{D(A, B), D(B, A)\}, & \text { if the maximum exists, } \\ +\infty, & \text { otherwise }\end{cases}
$$

for all $A, B \in C L(X)$. The following results are useful for some of the proofs in the paper.

Theorem 1.2 ([11]). If $(\mathrm{X}, \mathrm{d}, \mathrm{s})$ is a complete b-metric space with coefficient $\mathrm{s}$, then $(\mathrm{CL}(\mathrm{X}), \mathrm{H})$, where $\mathrm{H}$ means the Pompeiu-Hausdorff b-metric induced by $\mathrm{d}$, is also a complete b-metric space with coefficient $s$.

Lemma 1.3 ([11]). Let $(X, d, s)$ be a b-metric space with coefficient $s$ and $A, B \in C B(X)$. Then for each $a \in A$ and $\epsilon>0$ there exists $a \mathrm{~b} \in \mathrm{B}$ such that

$$
d(a, b) \leqslant H(A, B)+\epsilon .
$$

Lemma 1.4 ([11]). Let $(X, d, s)$ be a b-metric space with coefficient s. For any $A, B, C \in C L(X)$ and any $x, y \in X$, we have the following:

1. $d(x, A) \leqslant d(x, a)$ for all $a \in A$;

2. $d(x, B) \leqslant H(A, B)$ for all $x \in A$;

3. $d(x, A) \leqslant s[d(x, y)+d(y, A)]$

4. $H(A, C) \leqslant s[H(A, B)+H(B, C)]$;

5. $d(x, A)=0 \Leftrightarrow x \in A$.

Lemma 1.5 ([20]). Every sequence $\left(x_{n}\right)_{n \in \mathbb{N}}$ of elements from a b-metric space $(X, d, s)$, having the property that there exists $\gamma \in[0,1)$ such that

$$
d\left(x_{n+1}, x_{n}\right) \leqslant \gamma d\left(x_{n}, x_{n-1}\right)
$$

for every $\mathrm{n} \in \mathbb{N}$, is Cauchy.

Lemma $1.6([14])$. Let $(\mathrm{X}, \mathrm{d}, \mathrm{s})$ be a b-metric space and suppose that $\left(\mathrm{x}_{\mathrm{n}}\right)$ and $\left(\mathrm{y}_{\mathrm{n}}\right)$ converge to $\mathrm{x}, \mathrm{y} \in \mathrm{X}$, respectively. Then, we have

$$
\frac{1}{s^{2}} d(x, y) \leqslant \lim _{n \rightarrow \infty} \inf d\left(x_{n}, y_{n}\right) \leqslant \lim _{n \rightarrow \infty} \sup d\left(x_{n}, y_{n}\right) \leqslant s^{2} d(x, y)
$$

In particular, if $x=y$, then $\lim _{n \rightarrow \infty} \mathrm{d}\left(x_{n}, y_{n}\right)=0$. Moreover, for each $z \in X$, we have

$$
\frac{1}{s} d(x, z) \leqslant \lim _{n \rightarrow \infty} \inf d\left(x_{n}, z\right) \leqslant \lim _{n \rightarrow \infty} \sup d\left(x_{n}, z\right) \leqslant s d(x, z) .
$$

Definition 1.7 ([20]). A mapping $T: X \rightarrow C B(X)$, where $(X, d, s)$ is a b-metric space, is called closed if for all sequences $\left(x_{n}\right)_{n \in \mathbb{N}}$ and $\left(y_{n}\right)_{n \in \mathbb{N}}$ of elements from $X$ and $x, y \in X$ such that $\lim _{n \rightarrow \infty} x_{n}=x, \lim _{n \rightarrow \infty} y_{n}=y$, and $y_{n} \in T\left(x_{n}\right)$ for every $n \in \mathbb{N}$, we have $y \in T(x)$.

Definition 1.8 ([20]). Given a b-metric space $(X, d, s)$, the b-metric $d$ is called $*$-continuous if for every $A \in C B(X)$, every $x \in X$ and every sequence $\left(x_{n}\right)_{n \in \mathbb{N}}$ of elements from $X$ such that $\lim _{n \rightarrow \infty} x_{n}=x$, we have $\lim _{n \rightarrow \infty} d\left(x_{n}, A\right)=d(x, A)$. 


\section{The generalizations of Nadler contraction for multi-valued mappings}

In this section, we introduce the following condition of contractions for multi-valued mappings in b-metric space $(X, d)$. A map $T: X \rightarrow C B(X)$ is called weak quasi-contraction or $(\theta, k, L)$-quasi-contraction if there exist constant $\theta \in(0,1), k \in[0,1]$ and $L \geqslant 0$ such that

$$
H(T x, T y) \leqslant \theta M_{k, T}(x, y)+L d(y, T x)
$$

for all $x, y \in X$, where $M_{k, T}(x, y)=\max \{d(x, y), k d(x, T x), k d(y, T y)\}$.

Remark 2.1. Due to the symmetry of the distance, the weak quasi-contraction condition (2.1) implicitly includes the following dual one

$$
H(T x, T y) \leqslant \theta M_{1, T}(x, y)+\operatorname{Ld}(x, T y)
$$

for all $x, y \in X$, obtained from (2.1) by formally replacing $d(T x, T y)$ and $d(x, y)$ by $d(T y, T x)$ and $d(y, x)$, respectively, and then interchanging $x$ and $y$. Consequently, in the concrete applications it is necessary to check that both conditions (2.1) and (2.2) are satisfied.

Again as in [8], Aydi et al. [3, Theorem 2.2] introduced the q-set-valued quasi-contraction in the complete b-metric space. The multi-valued map $T: X \rightarrow C B(X)$ is said to be a q-multi-valued quasicontraction if

$$
H(T x, T y) \leqslant k M(x, y)
$$

for any $x, y \in X$, where $0 \leqslant k<1$ and

$$
M(x, y)=\max \{d(x, y), d(x, T x), d(y, T y), d(x, T y), d(y, T x)\} .
$$

Recently, Miculescu and Mihail [20, Theorem 3.3] used the following version of q-set-valued quasicontraction in the complete b-metric spaces. Let $\mathrm{T}: \mathrm{X} \rightarrow \mathrm{CB}(\mathrm{X})$ has a property that there exist $\mathrm{c}, \mathrm{d} \in[0,1]$ and $\alpha \in[0,1)$ such that

$$
H(T(x), T(y)) \leqslant \alpha N_{c, d}(x, y) \text { for all } x, y \in X,
$$

where

$$
N_{c, d}(x, y)=\max \left\{d(x, y), c d(x, T(x)), c d(y, T(y)), \frac{d}{2}(d(x, T(y))+d(y, T(x)))\right\} .
$$

Remark 2.2. Notice that since

$$
\frac{d(x, T y)+d(y, T x)}{2} \leqslant \max \{d(x, T y), d(y, T x)\}
$$

we then have that $N_{c, d}(x, y) \leqslant M(x, y)$ for all $x, y \in X$.

The following example shows that in b-metric spaces a weak quasi-contraction may not be a q-quasicontraction in the sense of Aydi et al. and may not be a contraction in the sense of Miculescu and Mihail.

Example 2.3. Let $X=\mathbb{R}, d(x, y)=(x-y)^{2}$ for all $x, y \in X$ and $T: X \rightarrow C B(X)$ be defined by $T x=\{x\}$. We obtain that $d$ is b-metric (with $s=2$ ), but $(X, d)$ is not a metric space. For $x=0, y=1$, and $z=2$, we have

$$
d(x, z)=4>2=d(x, y)+d(y, z) .
$$

Then $(X, d)$ is a complete $b$-metric space. Recall that for all $x, y \in X$,

$$
(x-y)^{2}=H(T x, T y) \leqslant a \max \{d(x, y), k d(x, T x), k d(y, T y)\}+L d(y, T x)=(a+L)(x-y)^{2}=(x-y)^{2}
$$

for $a=\frac{1}{6}, k=1$, and $L=\frac{5}{6}$, we have that $T$ satisfies condition (2.1) (note that $d(y, T x)=d(x, T y)$ ). Suppose that $T$ is a q-quasi-contraction in the sense of Aydi et al.. Thus, there exists $\alpha \in[0,1)$ such that for all $x, y \in X$,

$(x-y)^{2}=H(T x, T y) \leqslant \alpha \max \{d(x, y), d(x, T x), d(y, T y), d(x, T y), d(y, T x)\}=\alpha(x-y)^{2}<(x-y)^{2}$ if $x \neq y$. 
This is a contradiction. Similarly, suppose that $T$ is a q-quasi-contraction in the sense of Miculescu and Mihail. Thus, there exist $\mathrm{c}, \mathrm{d} \in[0,1]$ and $\alpha \in[0,1)$ such that:

$$
H(T(x), T(y)) \leqslant \alpha N_{c, d}(x, y) \text { for all } x, y \in X .
$$

So,

$$
\begin{aligned}
(x-y)^{2}=H(T x, T y) & \leqslant \alpha \max \left\{d(x, y), c d(x, T x), c d(y, T y), \frac{d}{2}(d(x, T y)+d(y, T x))\right\} \\
& =\alpha \max \left\{(x-y)^{2}, d(x-y)^{2}\right\}<(x-y)^{2} \text { if } x \neq y .
\end{aligned}
$$

This is a contradiction.

The aim of this paper is to obtain sufficient conditions for the existence of fixed point for the multivalued mappings which satisfy condition (2.1) in b-metric spaces.

\section{Main results}

The following theorem is our main result, which can be regarded as an extension of Nadler's fixed point theorem [21] in b-metric space.

Theorem 3.1. Let $(\mathrm{X}, \mathrm{d}, \mathrm{s})$ be a complete b-metric space and $\mathrm{T}: \mathrm{X} \rightarrow \mathrm{CB}(\mathrm{X})$ weak quasi-contraction for which there exist $\theta \in(0,1), \mathrm{k} \in[0,1]$ and $\mathrm{L} \geqslant 0$ such that

$$
H(T x, T y) \leqslant \theta \max \{d(x, y), k d(x, T x), k d(y, T y)\}+\operatorname{Ld}(y, T x)
$$

for all $x, y \in X$. Then there exists a sequence $\left(x_{n}\right)_{n \in \mathbb{N}}$ in $X$ which converges to some point $x^{*} \in X$ such that $x_{n+1} \in T\left(x_{n}\right)$ for every $n \in \mathbb{N}$. Also, $x^{*}$ is a fixed point of $T$ if any of the following conditions are satisfied:

(i) $\mathrm{T}$ is closed;

(ii) d is *-continuous;

(iii) $s \theta k<1$.

Proof. Let $x_{0} \in X$. Choose $x_{1} \in \mathrm{T} x_{0}$. Let

$$
\epsilon=\frac{1-\theta}{1+\theta} \mathrm{H}\left(\mathrm{T} x_{0}, \mathrm{~T} x_{1}\right)
$$

If $H\left(T x_{0}, T x_{1}\right)=0$, we obtain $T x_{0}=T x_{1}$ and $x_{1} \in T x_{1}$. In this case the proof is completed. So, we may assume $\epsilon>0$. From Lemma 1.3 we obtain that there is a point $x_{2} \in T x_{1}$ such that

$$
d\left(x_{1}, x_{2}\right) \leqslant H\left(T x_{0}, T x_{1}\right)+\epsilon=\frac{2}{1+\theta} H\left(T x_{0}, T x_{1}\right)
$$

Similarly, there is a point $x_{3} \in \mathrm{T} x_{2}$ such that

$$
d\left(x_{2}, x_{3}\right) \leqslant H\left(T x_{1}, T x_{2}\right)+\epsilon,
$$

where

$$
\epsilon=\frac{1-\theta}{1+\theta} \mathrm{H}\left(\mathrm{T} x_{1}, T x_{2}\right)
$$

If $\mathrm{H}\left(T x_{1}, T x_{2}\right)=0$, we obtain $T x_{2}=T x_{1}$ and $x_{2} \in T x_{2}$. In this case, the proof is completed. So, we may assume $\epsilon>0$. Hence,

$$
d\left(x_{2}, x_{3}\right) \leqslant \frac{2}{1+\theta} H\left(T x_{1}, T x_{2}\right) .
$$


Continuing this process we produce a sequence $\left(x_{n}\right)$ of points of $X$ such that

$$
x_{n+1} \in T x_{n} \text { for every } n \in \mathbb{N},
$$

and

$$
d\left(x_{n}, x_{n+1}\right) \leqslant \frac{2}{1+\theta} H\left(T x_{n-1}, T x_{n}\right) \text { for every } n \in \mathbb{N} .
$$

From condition (3.1), we obtain

$$
\begin{aligned}
H\left(T x_{n-1}, T x_{n}\right) & \leqslant \theta \max \left\{d\left(x_{n-1}, x_{n}\right), k d\left(x_{n-1}, T x_{n-1}\right), k d\left(x_{n}, T x_{n}\right)\right\}+\operatorname{Ld}\left(x_{n}, T x_{n-1}\right) \\
& \leqslant \theta \max \left\{d\left(x_{n-1}, x_{n}\right), k d\left(x_{n-1}, x_{n}\right), k d\left(x_{n}, x_{n+1}\right)\right\}+\operatorname{Ld}\left(x_{n}, x_{n}\right) \\
& =\theta \max \left\{d\left(x_{n-1}, x_{n}\right), k d\left(x_{n}, x_{n+1}\right)\right\} .
\end{aligned}
$$

If $\max \left\{d\left(x_{n-1}, x_{n}\right), k d\left(x_{n}, x_{n+1}\right)\right\}=k d\left(x_{n}, x_{n+1}\right)$, from (3.3) we obtain a contradiction $1<\frac{2 \theta k}{1+\theta}$. So,

$$
d\left(x_{n}, x_{n+1}\right) \leqslant \frac{2 \theta}{1+\theta} d\left(x_{n-1}, x_{n}\right) .
$$

Now, since $\frac{2 \theta}{1+\theta}<1$, from Lemma 1.5 we obtain that the sequence $\left(x_{n}\right)$ is a Cauchy sequence. Since $(X, d, s)$ is complete, the sequence $\left(x_{n}\right)$ converges to some point $x^{*} \in X$.

(i) Suppose that $T$ is closed. From Definition 1.7 and (3.2) we obtain $x^{*} \in T x^{*}$.

(ii) Suppose that $d$ is $*$-continuous. Then, we have

$$
\lim _{n \rightarrow \infty} d\left(x_{n}, T x^{*}\right)=d\left(x^{*}, T x^{*}\right) .
$$

From Lemma 1.4 and (3.1) we have

$$
\begin{aligned}
d\left(x_{n+1}, T x^{*}\right) \leqslant H\left(T x_{n}, T x^{*}\right) & \leqslant \theta \max \left\{d\left(x_{n}, x^{*}\right), k d\left(x_{n}, T x_{n}\right), k d\left(x^{*}, T x^{*}\right)\right\}+\operatorname{Ld}\left(x^{*}, T x_{n}\right) \\
& \leqslant \theta \max \left\{d\left(x_{n}, x^{*}\right), k d\left(x_{n}, x_{n+1}\right), k d\left(x^{*}, T x^{*}\right)\right\}+\operatorname{Ld}\left(x^{*}, x_{n+1}\right) .
\end{aligned}
$$

Hence, using (3.4) we obtain

$$
d\left(x^{*}, T x^{*}\right) \leqslant \theta k d\left(x^{*}, T x^{*}\right)
$$

Since $\theta k<1$, we conclude that $d\left(x^{*}, T x^{*}\right)=0$ and from Lemma 1.4 we obtain $x^{*} \in T x^{*}$.

(iii) We follow some ideas from [20]. Let

$$
\mathrm{d}\left(\mathrm{x}^{*}, \mathrm{~T}\left(\mathrm{x}^{*}\right)\right) \leqslant \varlimsup_{n \rightarrow \infty} \mathrm{d}\left(\mathrm{x}_{n}, \mathrm{~T}\left(\mathrm{x}^{*}\right)\right) .
$$

Then there exists a subsequence $\left(x_{n_{k}}\right)$ of $\left(x_{n}\right)$ such that for every $\epsilon>0$ there exists $k_{0} \in \mathbb{N}$ such that $d(u, T(u))-\epsilon \leqslant d\left(x_{n_{k+1}}, T(u)\right)$ for every $k \geqslant k_{0}$. Since

$$
d\left(x_{n+1}, T x^{*}\right) \leqslant \theta \max \left\{d\left(x_{n}, x^{*}\right), k d\left(x_{n}, x_{n+1}\right), k d\left(x^{*}, T x^{*}\right)\right\}+\operatorname{Ld}\left(x^{*}, x_{n+1}\right),
$$

using Lemma 1.6, we have

$$
\frac{1}{s} d\left(x^{*}, T x^{*}\right) \leqslant \theta k d\left(x^{*}, T x^{*}\right) .
$$

Since $s \theta k<1$, from the above inequality, we conclude that $d\left(x^{*}, T\left(x^{*}\right)\right)=0$, i.e. $x^{*} \in T\left(x^{*}\right)$, so $T$ has a fixed point. Now, let

$$
\mathrm{d}\left(\mathrm{x}^{*}, \mathrm{~T} x^{*}\right)>\varlimsup_{n \rightarrow \infty} \mathrm{d}\left(x_{n}, \mathrm{~T}\left(x^{*}\right)\right) .
$$

Then there exists $n_{0} \in \mathbb{N}$ such that for every $n \geqslant n_{0}$ we have

$$
d\left(x_{n}, T x^{*}\right) \leqslant d\left(x^{*}, T x^{*}\right) .
$$


So,

$$
\begin{aligned}
d\left(x^{*}, T x^{*}\right) & \leqslant s\left[d\left(x^{*}, x_{n+1}\right)+d\left(x_{n+1}, T x^{*}\right)\right] \\
& \leqslant s\left[d\left(x^{*}, x_{n+1}\right)+\theta \max \left\{d\left(x^{*}, x_{n}\right), k d\left(x_{n}, x_{n+1}\right), k d\left(x^{*}, T x^{*}\right)\right\}+\operatorname{Ld}\left(x^{*}, x_{n+1}\right)\right] .
\end{aligned}
$$

From the above inequality, when $n \rightarrow \infty$, we obtain

$$
d\left(x^{*}, T x^{*}\right) \leqslant \operatorname{s\theta kd}\left(x^{*}, T x^{*}\right) .
$$

Since $s \theta k<1$, we obtain $x^{*} \in T x^{*}$.

\section{Some applications}

We shall present some applications of Theorem 3.1 in b-metric spaces.

Corollary 4.1 (Version of Nadler's fixed point theorem in b-metric spaces, [21]). Let (X, d, s) be a complete $b$-metric space and $\mathrm{T}: \mathrm{X} \rightarrow \mathrm{CB}(\mathrm{X})$ a mapping satisfying

$$
H(T x, T y) \leqslant \theta d(x, y)
$$

for all $\mathrm{x}, \mathrm{y} \in \mathrm{X}$, where $\theta \in(0,1)$. Then $\mathrm{T}$ has a fixed point.

Proof. Put $\mathrm{k}=\mathrm{L}=0$ in Theorem 3.1.

Corollary 4.1 improves the next result by Czerwik [11].

Corollary 4.2. Let $(\mathrm{X}, \mathrm{d}, \mathrm{s})$ be a complete b-metric space and $\mathrm{T}: \mathrm{X} \rightarrow \mathrm{CB}(\mathrm{X})$ a mapping satisfying

$$
H(T x, T y) \leqslant \lambda d(x, y)
$$

for all $x, y \in X$, where $\lambda \in\left(0, \frac{1}{s}\right)$. Then $T$ has a fixed point.

Example 4.3. Let $X=[1,+\infty)$ be equipped with the complete b-metric $d$ such that $d(x, y)=(x-y)^{2}$ for all $x, y \in X$ (with coefficient $s=2$ ). Define $T: X \rightarrow C B(X)$ by $T x=\left[1,1+\frac{4 x}{5}\right]$ for all $x \in X$. Also, take $\theta=\frac{9}{16}$. We have

$$
H(T x, T y) \leqslant \theta d(x, y)
$$

for all $x, y \in X$, that is (4.1) holds. All hypotheses of Corollary 4.1 are satisfied and $x=1$ is a fixed point of $\mathrm{T}$.

On the other hand, Corollary 4.2 is not applicable. For $x=2$ and $y=1$, we have $H(T x, T y)=$ $\frac{16}{25}, d(x, y)=1$, so

$$
H(T x, T y)>\lambda d(x, y) \text { for all } \lambda \in\left[0, \frac{1}{2}\right) .
$$
have

Also, we may not apply the main result of Aydi et al. [3, Theorem 2.2]. Again, for $x=2$ and $y=1$, we

$$
d(x, T x)=0, d(y, T y)=0, d(x, T y)=0, d(y, T x)=0,
$$

so

$$
H(T x, T y)>\lambda \max \{d(x, y), d(x, T x), d(y, T y), d(x, T y), d(y, T x)\}
$$

for all $\lambda \in\left[0, \frac{1}{s^{2}+s}\right)$.

Corollary 4.4 (Version of fixed point theorem by Berinde [5] and Abbas et al. [1] in b-metric spaces). Let $(\mathrm{X}, \mathrm{d}, \mathrm{s})$ be a complete $b$-metric space and $\mathrm{T}: \mathrm{X} \rightarrow \mathrm{CB}(\mathrm{X})$ a weak contraction, i.e., there exist $\theta \in(0,1)$ and $\mathrm{L} \geqslant 0$ such that

$$
H(T x, T y) \leqslant \theta d(x, y)+\operatorname{Ld}(y, T x) \text { for all } x, y \in X
$$

Then T has a fixed point. 
Proof. Put $k=0$ in Theorem 3.1.

Example 4.5. Let $\mathrm{T}:[0,1] \rightarrow[0,1]$ defined by $\mathrm{T} x=\{x\}$ for all $x \in[0,1]$. Then

(i) T does not satisfy the contractive condition (2.3) of Aydi et al. [3];

(ii) T does not satisfy the contractive condition (2.4) of Miculescu and Mihail [20];

(iii) T satisfies condition (4.2) with $\theta \in(0,1)$ arbitrary and $L \geqslant 1-\theta$.

A weak contraction has always at least one fixed point and there exist weak contractions that have infinitely many fixed points.

Corollary 4.6 (Version of fixed point theorem by Kannan [17] in b-metric spaces). Let (X, $\mathrm{d}, \mathrm{s})$ be a complete $b$-metric space and $\mathrm{T}: \mathrm{X} \rightarrow \mathrm{CB}(\mathrm{X})$ a mapping for which there exists $\lambda \in\left(0, \frac{1}{2 \mathrm{~s}}\right)$ such that

$$
H(T x, T y) \leqslant \lambda[d(x, T x)+d(y, T y)] \text { for all } x, y \in X .
$$

Then T has a unique fixed point.

Proof. Put in Theorem $3.1 k=1$. Let $x, y \in X$ be arbitrary taken. We have to discuss three possible cases, but due to the symmetry of $M_{1, T}(x, y)$, it suffices to consider only two of them.

1. $M_{1, T}(x, y)=d(x, y)$. Then $d(x, T x) \leqslant d(x, y)$ and $d(y, T y) \leqslant d(x, y)$, hence from condition (4.3) we obtain

$$
\lambda[d(x, T x)+d(y, T y)] \leqslant 2 \lambda M_{1, T}(x, y) .
$$

Then conditions (2.1) and (2.2) are obviously satisfied (with $\theta=2 \lambda$ and $L=0$ ).

2. $M_{1, T}(x, y)=d(x, T x)$. Then $d(y, T y) \leqslant d(x, T x)$, so from condition (4.3) we have

$$
\lambda[d(x, T x)+d(y, T y)] \leqslant 2 \lambda M_{1, T}(x, y) .
$$

Then condition (2.1) holds for $\theta=2 \lambda$ and $L=0$. So (2.2) also holds.

Therefore both (2.1) and (2.2) hold with $\theta=2 \lambda$ and $L=0$. Now, from Theorem 3.1 we conclude that the mapping $\mathrm{T}$ has a fixed point $x^{*}$ if $2 \lambda s<1$ (condition (iii) in Theorem 3.1). Let $y^{*}$ be a fixed point of the mapping $T$. Then, from condition (4.3) we obtain

$$
d\left(x^{*}, y^{*}\right) \leqslant H\left(T x^{*}, y^{*}\right) \leqslant \lambda\left[d\left(x^{*}, T x^{*}\right)+d\left(y^{*}, T y^{*}\right)\right]=0,
$$

so $x^{*}=y^{*}$.

Corollary 4.7 (Version of fixed point theorem by Chatterjea [6] in b-metric spaces). Let ( $\mathrm{X}, \mathrm{d}, \mathrm{s})$ be a complete $b$-metric space and $\mathrm{T}: \mathrm{X} \rightarrow \mathrm{CB}(\mathrm{X})$ a mapping for which there exists $\lambda \in\left(0, \frac{1}{\mathrm{~s}+\mathrm{s}^{2}}\right)$ such that

$$
H(T x, T y) \leqslant \lambda[d(x, T y)+d(y, T x)] \text { for all } x, y \in X .
$$

Then T has a unique fixed point.

Proof. By (4.4) and triangle rule we have

$$
\begin{aligned}
H(T x, T y) & \leqslant \lambda s[d(x, y)+s(d(y, T x)+H(T x, T y))+\lambda d(y, T x) \\
& \leqslant \lambda s d(x, y)+\lambda\left(s^{2}+1\right) d(y, T x)+\lambda s^{2} H(T x, T y) .
\end{aligned}
$$

After simple computations, we get

$$
H(T x, T, y) \leqslant \frac{\lambda s}{1-\lambda s^{2}} d(x, y)+\frac{\lambda\left(s^{2}+1\right)}{1-\lambda s^{2}} d(y, T x),
$$


which is (4.2), with $\theta=\frac{\lambda s}{1-\lambda s^{2}}$ (since $\lambda<\frac{1}{s+s^{2}}$ ) and $L=\frac{\lambda\left(s^{2}+1\right)}{1-\lambda s^{2}} \geqslant 0$. So, from Corollary 4.4 we obtain that $\mathrm{T}$ has a fixed point $x^{*}$. If $\mathrm{y}^{*}$ is also a fixed point of $\mathrm{T}$, from condition (4.4) we obtain

$$
d\left(x^{*}, y^{*}\right) \leqslant H\left(T x^{*}, y^{*}\right) \leqslant \lambda\left[d\left(x^{*}, T y^{*}\right)+d\left(y^{*}, T x^{*}\right)\right] \leqslant \lambda\left[d\left(x^{*}, y^{*}\right)+d\left(y^{*}, x^{*}\right)\right]<2 \lambda d\left(x^{*}, y^{*}\right)<d\left(x^{*}, y^{*}\right) .
$$

It is a contradiction if $x^{*} \neq y^{*}$.

Corollary 4.8 (Generalizations of fixed point theorem by Reich in b-metric spaces, [22]). Let (X, d, s) be a complete b-metric space and $\mathrm{T}: \mathrm{X} \rightarrow \mathrm{CB}(\mathrm{X})$ a mapping satisfying

$$
H(T x, T y) \leqslant \theta \max \{d(x, y), d(x, T x), d(y, T y)\}
$$

for all $x, y \in X$, where $\theta \in\left(0, \frac{1}{s}\right)$. Then $T$ has a fixed point.

Proof. Put $\mathrm{k}=1, \mathrm{~L}=0$ in Theorem 3.1.

Corollary 4.9 (Version of fixed point theorem by Ćirić $[7,8])$. Let $(X, d, s)$ be a complete $b$-metric space and $\mathrm{T}: \mathrm{X} \rightarrow \mathrm{CB}(\mathrm{X})$ a mapping satisfying

$$
H(T x, T y) \leqslant \alpha M(x, y)
$$

where $\alpha \in\left(0, \frac{1}{2 s}\right)$. Then $\mathrm{T}$ has a fixed point.

Proof. Let $x, y \in X$ be arbitrary taken. We will use Theorem 3.1. We have to discuss five possible cases, but due to the symmetry of $M(x, y)$, it suffices to consider only three of them.

1. $M(x, y)=d(x, y)$. Then $M(x, y)=M_{1, T}(x, y)$, so condition (2.1) and its dual condition (2.2) are obviously satisfied with $\theta=\alpha$ and $L=0$.

2. $M(x, y)=d(x, T x)$. And in this case we have $M(x, y)=M_{1, T}(x, y)$, so $\theta=\alpha$ and $L=0$.

3. $M(x, y)=d(y, T x)$. From (4.5) we get

$$
H(T x, T y) \leqslant \alpha d(y, T x) \leqslant \theta M_{1, T}(x, y)+\alpha d(y, T x),
$$

so (2.1) holds with $\theta \in(0,1)$ and $L=\alpha$. Since,

$$
H(T x, T y) \leqslant \alpha M(x, y)=\alpha d(y, T x) \leqslant \alpha s[d(y, T y)+H(T y, T x)] \leqslant \alpha s\left[M_{1, T}(x, y)+H(T x, T y)\right],
$$

we get

$$
H(T x, T y) \leqslant \frac{\alpha s}{1-\alpha s} M_{1, T}(x, y) .
$$

So, dual (2.2) also holds for all $\theta=\frac{\alpha s}{1-\alpha s}$ and $L=0$. Therefore both (2.1) and its dual (2.2) hold with

$$
\theta=\max \left\{\alpha, 0, \frac{\alpha s}{1-\alpha s}\right\}=\frac{\alpha s}{1-\alpha s}, \quad L=\max \{0, \alpha\}=\alpha .
$$

Since $\alpha \in\left(0, \frac{1}{2 s}\right)$, we obtain that $\theta s<1$ and $L>0$. Therefore, from Theorem 3.1, it follows that $T$ has a fixed point.

\section{Remark 4.10.}

(i) Note that $\left(0, \frac{1}{s+s^{2}}\right) \subseteq\left(0, \frac{1}{2 s}\right)$ implies that Corollary 4.9 implies the main result in [3, Theorem 2.2].

(ii) In [2, Theorem 2.2] Amini-Harandi proved the following result in metric spaces.

Theorem 4.11. Let $(\mathrm{X}, \mathrm{d})$ be a complete metric space and $\mathrm{T}: \mathrm{X} \rightarrow \mathrm{CB}(\mathrm{X})$ be a mapping satisfying

$$
H(T x, T y) \leqslant \alpha M(x, y),
$$

where $\alpha \in\left(0, \frac{1}{2}\right)$. Then $\mathrm{T}$ has a fixed point.

Note that from Corollary 4.9 we obtain Theorem 4.11 .

Problem 4.12. Does the conclusion of Corollary 4.9 remain true for any $\alpha \in\left[\frac{1}{2 s}, 1\right)$ ? 


\section{References}

[1] M. Abbas, N. Hussain, B. E. Rhoades, Coincidence point theorems for multivalued f-weak contraction mappings and applications, Rev. R. Acad. Cienc. Exactas Fs. Nat. Ser. A Math. RACSAM, 105 (2011), 261-272. 4.4

[2] A. Amini-Harandi, Fixed point theory for set-valued quasi-contraction maps in metric spaces, Appl. Math. Lett., 24 (2011), 1791-1794. 4.10

[3] H. Aydi, M. F. Bota, E. Karapınar, S. Mitrović, A fixed point theorem for set-valued quasi-contractions in b-metric spaces, Fixed Point Theory Appl., 2012 (2012), 8 pages.. 1, 1, 2, 4.3, 4.5, 4.10

[4] I. A. Bakhtin, The contraction mapping principle in almost metric space, (Russian) Functional analysis, Ulyanovsk. Gos. Ped. Inst., Ulyanovsk, 30 (1989), 26-37. 1

[5] M. Berinde, V. Berinde, On a general class of multi-valued weakly Picard mappings, J. Math. Anal. Appl., 326 (2007), 772-782. 4.4

[6] S. K. Chatterjea, Fixed-point theorems, C. R. Acad. Bulgare Sci., 25 (1972), 727-730. 4.7

[7] L. B. Ćirić, Generalized contractions and fixed-point theorems, Publ. Inst. Math. (Beograd) (N.S.), 12 (1971), 19-26. 4.9

[8] L. B. Ćirić, A generalization of Banach's contraction principle, Proc. Amer. Math. Soc., 45 (1974), 267-273. 2, 4.9

[9] M. Cosentino, P. Salimi, P. Vetro, Fixed point results on metric-type spaces, Acta Math. Sci. Ser. B Engl. Ed., 34 (2014), 1237-1253. 1

[10] S. Czerwik, Contraction mappings in b-metric spaces, Acta Math. Inform. Univ. Ostraviensis, 1 (1993), 5-11. 1, 1

[11] S. Czerwik, Nonlinear set-valued contraction mappings in b-metric spaces, Atti Sem. Mat. Fis. Univ. Modena, 46 (1998), 263-276. 1, 1, 1.2, 1.3, 1.4, 4

[12] N. Hussain, A. Amini-Harandi, J. Y. Cho, Approximate endpoints for set-valued contractions in metric spaces, Fixed Point Theory Appl., 2010 (2010), 13 pages.

[13] N. Hussain, D. Dorić, Z. Kadelburg, S. Radenović, Suzuki-type fixed point results in metric type spaces, Fixed Point Theory Appl., 2012 (2012), 12 pages.

[14] N. Hussain, V. Parvaneh, J. R. Roshan, Z. Kadelburg, Fixed points of cyclic weakly $(\psi, \varphi, \mathrm{L}, \mathrm{A}, \mathrm{B})$-contractive mappings in ordered b-metric spaces with applications, Fixed Point Theory Appl., 2013 (2013), 18 pages. 1.6

[15] N. Hussain, R. Saadati, R. P. Agrawal, On the topology and wt-distance on metric type spaces, Fixed Point Theory Appl., 2014 (2014), 14 pages.

[16] N. Hussain, M. H. Shah, KKM mappings in cone b-metric spaces, Comput. Math. Appl., 62 (2011), 1677-1684. 1

[17] R. Kannan, Some results on fixed points, Bull. Calcutta Math. Soc., 60 (1968), 71-76. 4.6

[18] M. A. Khamsi, Remarks on cone metric spaces and fixed point theorems of contractive mappings, Fixed Point Theory Appl., 2010 (2010), 7 pages. 1

[19] M. A. Khamsi, N. Hussain, KKM mappings in metric type spaces, Nonlinear Anal., 73 (2010), 3123-3129. 1

[20] R. Miculescu, A. Mihail, New fixed point theorems for set-valued contractions in b-metric spaces, J. Fixed Point Theory Appl., (2015), 1-11. 1.5, 1.7, 1.8, 2, 3, 4.5

[21] S. B. Nadler, Jr., Multi-valued contraction mappings, Pacific J. Math., 30 (1969), 475-488. 3, 4.1

[22] S. Reich, Some remarks concerning contraction mappings, Canad. Math. Bull., 14 (1971), 121-124. 4.8

[23] J. R. Roshan, V. Parvaneh, I. Altun, Some coincidence point results in ordered b-metric spaces and applications in a system of integral equations, Appl. Math. Comput., 226 (2014), 725-737. 1

[24] J. R. Roshan, V. Parvaneh, S. Radenović, M Rajović, Some coincidence point results for generalized $(\psi, \varphi)$-weakly contractions in ordered b-metric spaces, Fixed Point Theory Appl., 2015 (2015), 21 pages.

[25] J. R. Roshan, V. Parvaneh, S. Sedghi, N. Shobkolaei, W. Shatanawi, Common fixed points of almost generalized $(\psi, \varphi)_{\mathrm{s}^{-}}$ contractive mappings in ordered b-metric spaces, Fixed Point Theory Appl., 2013 (2013), 23 pages.

[26] S. Shukla, S. Radenović, C. Vetro, Set-valued Hardy-Rogers type contraction in 0-complete partial metric spaces, Int. J. Math. Math. Sci., 2014 (2014), 9 pages. 1 